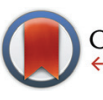

CrossMark \& click for updates

Cite this: Polym. Chem., 2016, 7, 553

\title{
An aromatic/aliphatic polyester prepared via ring-opening polymerisation and its remarkably selective and cyclable depolymerisation to monomer $\dagger$
}

\author{
Jarret P. MacDonald and Michael P. Shaver* \\ The ring-opening polymerisation of 2,3-dihydro-5H-1,4-benzodioxepin-5-one (2,3-DHB) with aluminium \\ salen or organocatalysts gives polyester homopolymers and copolymers with L-lactide or rac- $\beta$-butyro- \\ lactone that contain both aromatic and aliphatic linkages, the first polymers with an aromatic ring in the \\ backbone prepared by this key method. The same Al salen catalyst catalyses a remarkably selective de- \\ polymerisation to monomer under modified reaction conditions. The process may be cycled to repeat- \\ edly recycle polymer to monomer and maintain the polymer's low dispersity.
}

Received 6th October 2015

Accepted 11th November 2015

DOI: $10.1039 / c 5 p y 01606 a$

www.rsc.org/polymers

\section{Introduction}

The exceptional growth in both fundamental research and industrial importance of (bio)degradable polymers stems from the controlled ring-opening polymerisation (ROP) of $\varepsilon$-caprolactone $(\varepsilon-\mathrm{CL})$, lactide $(\mathrm{LA})$ and $\beta$-butyrolactone $\left(\beta\right.$-BL). ${ }^{1}$ Challenges remain as the resultant polyesters (i.e. poly(lactic acid), PLA) often have non-ideal thermal properties, slow hydrolytic degradation and industrial enzymatic composting to degrade to lactic acid rather than the original cyclic ester. Many elegant strategies exist to both expand scope and tune polymer properties including control of microstructure, ${ }^{2-5}$ macrostructure ${ }^{6-11}$ and composition. ${ }^{12-22}$ This includes mimicry of petroleum-derived polymers such as the ROP of macrolactones that introduce long polyolefin-like segments into polyester repeat units to prepare polyethylene-like structures ${ }^{23-29}$ including high molecular weight polymacrolactones prepared using aluminium salen catalysts..$^{30,31}$

Pioneering work extended mimicry in monomer design to the incorporation of aromatic substituents ${ }^{32,33}$ when Baker polymerised phenyllactide ${ }^{34}$ and mandelide ${ }^{35}$ to introduce pendant phenyl rings and produce polymers akin to polystyrene. Poly(mandelic acid) was later prepared via the ROP of 5-phenyl-1,3-dioxolane-2,4-dione with concomitant loss of $\mathrm{CO}_{2},{ }^{36}$ which was extended to high molecular weight stereoregular polymers using organocatalysts. ${ }^{37}$

EaStCHEM, School of Chemistry, University of Edinburgh, Joseph Black Building, EH9 3JF, David Brewster Road, Edinburgh, UK. E-mail: michael.shaver@ed.ac.uk $\dagger$ Electronic supplementary information (ESI) available: Experimental procedures, NMR characterisation, polymerisation data. See DOI: 10.1039/ c5py01606a
Introduction of aromatic functionalities within the polymer backbone rather than pendant to the chain is more exceptional. While a copolymerisation of styrene oxide with phthalic anhydride has been published, ${ }^{38}$ there have been no reports of polymers prepared via cyclic ester ROP that incorporate phenyl moieties into the polymer backbone. This is surprising as many aromatic polyesters such as poly(ethylene terephthalate) (PET), are important commodity plastics. This work has been extended to include other epoxides, ${ }^{39}$ as well as replacing phthalic anhydride with an ester, dihydrocoumarin. ${ }^{40}$

The synthesis of PET and similar aromatic/aliphatic polyesters has been achieved through ROP. ${ }^{41}$ This method involved first synthesising cyclic oligomers from monomers, which are then used in ROP. While this allowed for synthesis of a wide range of alkylene phthalate polymers, reactions required high temperatures and resulted in broad dispersities. Recent advances in this field have investigated catalyst choice, broadening monomer scope and copolymerisation. ${ }^{42-55}$ Despite such advances, the polymerisations were typically uncontrolled and required synthesis of oligomers with varying size before polymerisation.

We thus targeted the production of polyesters that contained an aromatic and aliphatic linkage in the polymer backbone that could be readily synthesised from a well-defined monomer, identifying the benzodioxepinones as a class of aromatic cyclic esters that may serve as monomers for ROP. In particular, 2,3-dihydro-5 $H$-1,4-benzodioxepin-5-one (2,3-DHB) is commercially available and facile to synthesise. ${ }^{56-58}$ Additionally, a highly enantioselective synthesis of substituted 2,3-DHBs suggested a potentially broad monomer scope. ${ }^{59,60}$ We hypothesised that 2,3-DHB would undergo ROP (Scheme 1) in a manner similar to other seven-membered cyclic esters 


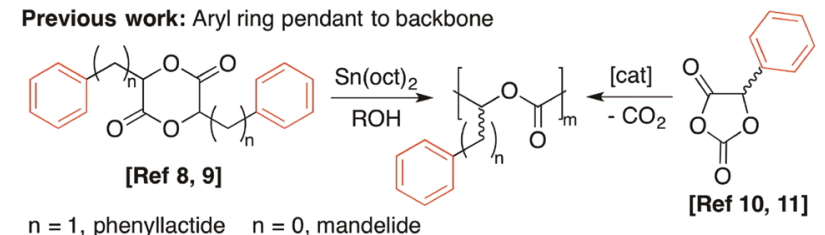

$\mathrm{n}=1$, phenyllactide $\mathrm{n}=0$, mandelide
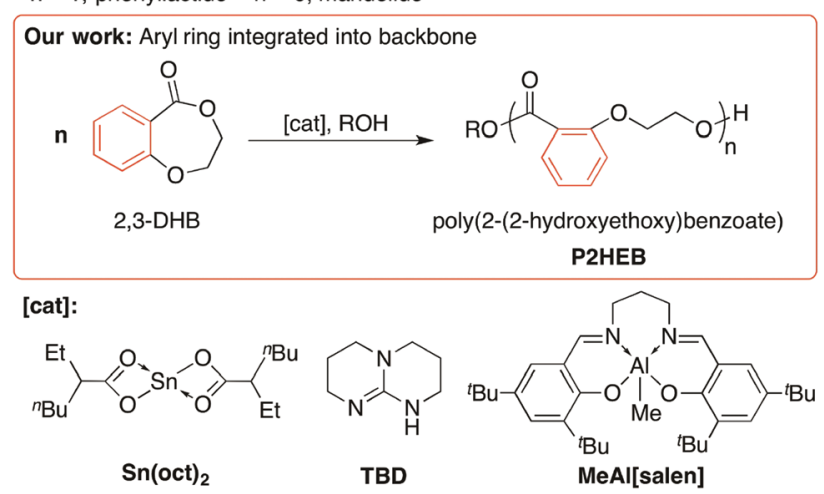

Scheme 1 Polymerisation of phenyllactide, mandelide, 5-phenyl-dioxolanedione and, in this work, benzodioxipinone monomers to prepare polyesters with pendant (poly(phenyllactic acid), poly(mandelic acid)) and backbone-incorporated (poly(2-2-hydroxyethoxybenzoate) phenyl substituents using organo- and metal-based cataylsts.

(i.e. $\varepsilon$-CL) whose ROP reactions are readily controlled to high conversion by judicious choice of catalyst. ${ }^{61-67}$

\section{Results and discussion}

\section{Homopolymerisation of 2,3-DHB}

Polymerisation of 2,3-DHB using $\mathrm{Sn}(\mathrm{oct})_{2}$ gave no or low monomer conversion to poly(2-(2-hydroxyethoxy)benzoate), $\mathrm{P} 2 \mathrm{HEB}$, at $70-120{ }^{\circ} \mathrm{C}$ (Table $\mathrm{S} 1 \dagger$ ). Longer reaction times did not significantly increase conversion but did promote a loss of control. Higher polymer dispersities $(\theta=1.44)$ suggested transesterification dominated after polymer-monomer equilibrium was established. The relatively low solubility of P2HEB in THF means that $\mathrm{d} n / \mathrm{d} c$ values would be inaccurate. We thus report molecular weights calculated by relative integration of benzylic end-group resonances to polymer resonances.

Aluminium salen complexes are excellent catalysts for ROP and exhibit a lower tendency towards transesterification than tin catalysts. ${ }^{68,69}$ Switching to an aluminium salen complex, MeAl[salen], gave much improved 2,3-DHB polymerisation (Fig. S2, Table S2 $\dagger$ ) after optimisation. Bulk and solution polymerisations conducted at $120{ }^{\circ} \mathrm{C}$ were uncontrolled $(\nexists>1.6)$ and reached a maximum conversion of $66 \%$. Furthermore, solution polymerisations required a high initial 2,3-DHB concentration $\left([2,3-\mathrm{DHB}]_{0}\right)$; no productive polymerisation was observed under dilute conditions. Interestingly, decreasing the polymerisation temperature to $70{ }^{\circ} \mathrm{C}$ solved these challenges. Neat polymerisation at $70{ }^{\circ} \mathrm{C}$ for one hour yielded $\mathrm{P} 2 \mathrm{HEB}$ with $64 \%$ conversion, low $D(1.13)$ and predictable molecular weights. Performing the reaction in toluene for one hour
Table 1 Polymerisation of 2,3-DHB with an aluminum salen complex ${ }^{a}$

\begin{tabular}{lclllll}
\hline$T\left({ }^{\circ} \mathrm{C}\right)$ & Time $(\mathrm{h})$ & {$[\mathrm{M}]_{\mathrm{o}} /[\mathrm{Al}]_{\mathrm{o}}$} & Conv. $^{b}(\%)$ & $M_{\mathrm{n}, \mathrm{th}}{ }^{c}$ & \multicolumn{1}{c}{$M_{\mathrm{n}}{ }^{b}$} & $\Xi^{d}$ \\
\hline 60 & 4 & 100 & 92 & 15270 & 13000 & 1.08 \\
60 & 6 & 100 & 92 & 15270 & 13500 & 1.09 \\
50 & 6 & 100 & 91 & 15060 & 15220 & 1.07 \\
50 & 24 & 200 & 88 & 28870 & 25210 & 1.10 \\
50 & 24 & 500 & 78 & 63740 & 52050 & 1.11 \\
22 & 6 & 50 & 80 & 6690 & 6790 & 1.13 \\
22 & 6 & 200 & 46 & 15350 & 14210 & 1.12 \\
22 & 24 & 200 & 85 & 27910 & 27010 & 1.11
\end{tabular}

${ }^{a} 2.3$-DHB polymerisation conducted in toluene $(1: 1 \mathrm{~m} / \mathrm{m})$. ${ }^{b}$ Determined by ${ }^{1} \mathrm{H}$ NMR spectroscopy. ${ }^{c} M_{\mathrm{n}, \mathrm{th}}=\left([2,3-\mathrm{DHB}]_{0} /\right.$ $\left.[\mathrm{BnOH}]_{0}\right) \times \%$ conversion $\times \mathrm{MW}_{2,3-\mathrm{DHB}} \cdot{ }^{d}$ Determined by gel permeation chromatography (details in ESI).

resulted in a modest increase in conversion (75\%) with only a slight increase in $Ð$ (1.16). Extending the polymerisation time to three hours under identical conditions yielded no significant change in polymer characteristics. Decreasing the temperature minimised transesterification side reactions. Building on this promising result, the Al-mediated ROP was explored (Table 1). Polymerisations were exceptionally well controlled while reaching higher conversion when $T \leq 60^{\circ} \mathrm{C}$, even permitting room temperature ROP. Higher molecular weight P2HEB was also synthesised by increasing $[2,3-\mathrm{DHB}]_{0}:[\mathrm{Al}]_{0}:[\mathrm{BnOH}]_{0}$ to $200: 1: 1$ and $500: 1: 1$ without sacrificing polymerisation control.

\section{Monomer equilibrium and P2HEB depolymerisation}

The odd observation of higher conversions at lower temperatures can be explained by the monomer-polymer equilibrium. That is, the relative rate of transesterification leading to depolymerisation $\left(k_{\mathrm{d}}\right)$ compared to rate of productive transesterification polymerisation $\left(k_{\mathrm{p}}\right)$ increases when $T \geq 70{ }^{\circ} \mathrm{C}$, shifting the equilibrium towards higher [2,3-DHB], the importance of which was noted in a recent paper on the ROP of morpholinones. ${ }^{70}$ In our study, we verified this equilibrium by performing a variable temperature NMR scale polymerisation (see ESI $\dagger$ ). Polymerisation of 50 eq. of 2,3-DHB at room temperature gave an NMR conversion of $88 \%$. Subsequent heating of the sample for 10 hours at $90{ }^{\circ} \mathrm{C}$ resulted in a decrease in conversion $(70 \%)$ with an increase in monomer signals, indicating depolymerisation had occurred with no apparent degradation.

As mentioned previously, performing polymerisations under dilute conditions resulted in no conversion; successful polymerisations mediated by $\mathrm{MeAl}[\mathrm{salen}]$ were conducted at $[2,3-\mathrm{DHB}]_{0}$ of $4-5 \mathrm{M}$. We noted that it was possible to polymerise at lower concentrations using organocatalysts (Table S3†). While basic or acidic organocatalysts 1,8-diazabicyclo[5.4.0]undec-7-ene (DBU) and diphenyl phosphate (DPP) respectively, did not yield any polymer, the bifunctional 1,5,7triazabicyclo[4.4.0]dec-5-ene (TBD) catalysed a very well controlled polymerisation at relatively rapid rates (Table $\mathrm{S} 4 \dagger$ ) even under much lower concentrations. Polymerisations at $2.4 \mathrm{M}$ reached $87 \%$ after just 30 minutes. Decreasing $[2,3-\mathrm{DHB}]_{0}$ 
further to 1.3 and $0.5 \mathrm{M}$ decreased polymer conversion to 80 and $51 \%$, respectively as the polymer-monomer equilibrium favoured depolymerisation at lower concentrations.

Beyond the novelty of the first aromatic backbone components accessed through cyclic ester monomer ROP, these two observations led us to the most interesting feature of this polymerisation system: a clean, reversible and cyclable depolymerisation. While depoylemerisation of aliphatic polyesters is observed in other systems, it is not typically selective. ${ }^{65,71,72}$ As a result, oligomers are typically produced. The synthesis of lactide from PLA can be achieved through ring-closing depolymerisation (Scheme 2), though a high degree of depolymerisation is driven by the removal of monomer by distillation. ${ }^{73}$ For the MeAl[salen] catalyst we observed both a temperature dependent and concentration dependent monomer/polymer equilibrium (vide supra). When we exploit only concentration, depolymerisation occurs selectively to monomer with no oligomers observed. To demonstrate this, P2HEB homopolymer was synthesised and purified to remove any residual monomer. $\mathrm{P} 2 \mathrm{HEB}$ was then added to $\mathrm{MeAl}\left[\right.$ salen] in toluene at $60^{\circ} \mathrm{C}$ for six hours. Two methods were used to establish the equilibrium monomer concentration of P2HEB. First, this was done by polymerisation of 2,3-DHB (Table S9†). In a glovebox, 2,3-DHB polymerisation was set up as described previously at three different $[2,3-\mathrm{DHB}]_{0}$. The polymerisations were continued for

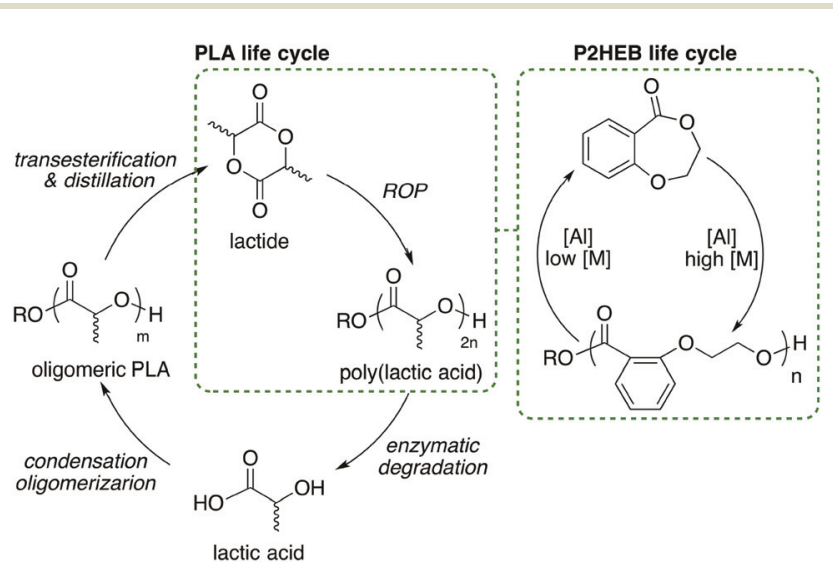

Scheme 2 Idealized life cycles of poly(lactic acid) and poly(2-(2-hydroxyethoxy)benzoate) moving from four energy intensive steps in PLA recycling to simple ring-opening polymerization and ring closing depolymerization steps for $\mathrm{P} 2 \mathrm{HEB}$. six hours at $60{ }^{\circ} \mathrm{C}$. After six hours, ${ }^{1} \mathrm{H}$ NMR spectroscopy was used to calculate relative $[2,3-\mathrm{DHB}]:[\mathrm{P} 2 \mathrm{HEB}]$ and consequently $[2,3-\mathrm{DHB}]_{\mathrm{eq}}$. Longer times did not change conversion. It was also calculated by depolymerisation (Table S10 $\dagger$ ). Solutions of $\mathrm{MeAl}[\mathrm{salen}](1.4 \mathrm{~mol} \%)$ and three different [P2HEB] in $\mathrm{C}_{6} \mathrm{D}_{6}$ were heated to $60{ }^{\circ} \mathrm{C}$ for 12 hours and analysed by ${ }^{1} \mathrm{H}$ NMR spectroscopy. Using relative integration of [P2HEB] : [2,3-DHB] and initial concentration, $[2,3-\mathrm{DHB}]_{\mathrm{eq}}$ was calculated. By both methods, $[\mathrm{P} 2 \mathrm{HEB}]_{\mathrm{eq}}$ was $0.36 \mathrm{M}$ at $60^{\circ} \mathrm{C}$ in toluene.

We established a $0.17 \mathrm{M}[\mathrm{P} 2 \mathrm{HEB}]_{0}$ and selectively converted to 2,3 -DHB $(>90 \%)$ in $<12$ hours (Fig. S2, Table S6†). Importantly, this behaviour is unique to this new polymer and does not occur with poly(lactic acid)s under similar conditions with this catalyst system. The MeAl[salen] catalyst is also essential as subjecting $\mathrm{P} 2 \mathrm{HEB}$ to similar conditions in the presence of TBD did not yield significant 2,3-DHB $(\leq 5 \%)$ after 12 hours at $60{ }^{\circ} \mathrm{C}$, instead leading to transesterified polymer products.

We envisage this control being beneficial in the life cycle of the polymer as monomer can be recovered directly, bypassing hydroxyacids as intermediates in energy-intensive monomer synthesis. In the case of $\mathrm{Al}$, the same catalyst can be used for polymerisation and depolymerisation (Scheme 2).

To exemplify reversibility, a one-pot reaction was run with an initial monomer concentration of $4.1 \mathrm{M}$. After $6 \mathrm{~h}$ at $60^{\circ} \mathrm{C}$, conversion to P2HEB was $82 \%$ (entry 1, Table 2). Addition of toluene gave an apparent $[2,3-\mathrm{DHB}]_{0}$ of $0.2 \mathrm{M}$ and resulted in a depolymerisation with 2,3-DHB: $\mathrm{P} 2 \mathrm{HEB}=94: 6$ (entry 2, Table 2). Reconcentration of the reaction in vacuo to give an apparent $[2,3-\mathrm{DHB}]_{0}$ of $4.1 \mathrm{M}$ resulted in $84 \%$ conversion to $\mathrm{P} 2 \mathrm{HEB}$ after heating to $60{ }^{\circ} \mathrm{C}$ for $6 \mathrm{~h}$. The polymerisation is nearly fully reversible and that the depolymerisation yields monomer with a surprisingly high degree of purity. Importantly, no degradation products are produced, allowing for clean repolymerisation with exceptional levels of control over dispersity and molecular weight.

Excellent retention of control upon repolymerisation is also exemplified by gel permeation chromatography (GPC) of the crude samples (Fig. 1). The trace corresponding to entry 2 shows that polymer has been converted near quantitatively to monomer (94\%).

\section{Copolymers with P2HEB}

Finally, we wanted to extend the utility of this new monomer and the livingness of the ROP by incorporating 2,3-DHB into

Table 2 Concentration dependent reversibility of 2,3-DHB polymerization ${ }^{a}$

\begin{tabular}{llllrr}
\hline Entry & Concentration $^{b}(\mathrm{M})$ & $2,3-\mathrm{DHB}^{c}(\%)$ & P2HEB $^{c}(\%)$ & $M_{\mathrm{n}, \mathrm{th}}{ }^{d}$ & $M_{\mathrm{n}}{ }^{e}$ \\
1 & 4.1 & 18 & 82 & 13600 & 1100 \\
2 & 0.2 & 94 & 06 & 12200 & 1090 \\
3 & 4.1 & 16 & 84 & 13850 & 1.08 \\
& & & 1.09 & 13720
\end{tabular}

${ }^{a}$ One-pot polymerization-depolymerization of $2,3-\mathrm{DHB} / \mathrm{P} 2 \mathrm{HEB}$ by varying concentration with $[2,3-\mathrm{DHB}]_{0}:[\mathrm{Al}]_{0}:[\mathrm{BnOH}]_{0}=100: 1: 1$.

${ }^{b}$ Concentration $=[2,3-\mathrm{DHB}]_{0} /$ volume toluene. ${ }^{c}$ Determined by gel permeation chromatography. ${ }^{d} M_{\mathrm{n}, \mathrm{th}}=\left([2,3-\mathrm{DHB}]_{0} /[\mathrm{BnOH}]_{0}\right) \times \%$ conversion $\times$ $\mathrm{MW}_{2,3 \text {-DHB. }}{ }^{e}$ Determined by ${ }^{1} \mathrm{H}$ NMR spectroscopy. 


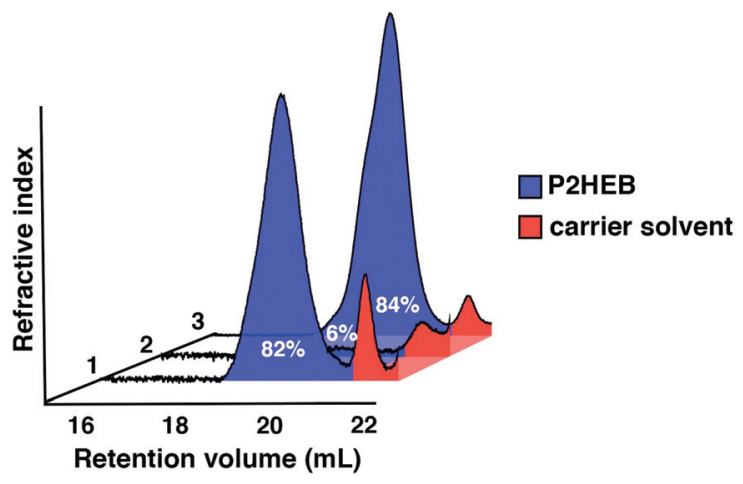

Fig. 1 GPC traces of crude samples from entries 1, 2 and 3.

copolymers. $\mathrm{AB}$ diblock and $\mathrm{ABA}$ triblock copolymers are readily prepared by sequential monomer addition. Polymerisation of 2,3-DHB was followed by addition of L-LA and an increase in reaction temperature to incorporate the more inert lactide monomer. The copolymerisation reactions were high yielding and well controlled (Tables S5 and S6 $\dagger$ ). ${ }^{1} \mathrm{H}$ NMR spectroscopy of the $\mathrm{P}(\mathrm{L}-\mathrm{LA})$ methine region suggested that the copolymers had undergone some scrambling (Fig. S1†) indicating the $\mathrm{AB}$ copolymers were likely gradient copolymers instead of true block copolymers. $\mathrm{AB}$ block copolymers were prepared using a monofunctional alcohol initiator $(\mathrm{BnOH})$ while $\mathrm{ABA}$ block copolymers were synthesised using a propanediol core to build the central P2HEB mid-block followed by growth of the two PLA A blocks. Sequential addition of 2,3-DHB to growing poly(3-hydroxybutyrate), $\mathrm{P} 3 \mathrm{HB}$, resulted in the $\mathrm{AB}$ block copolymer $\mathrm{P}(3 \mathrm{HB}-b-2 \mathrm{HEB})$. Scrambling was unlikely in this copolymer as the P2HEB block is grown onto the P3HB block.

The scrambling of P2HEB/PLA in copolymers made depolymerisation of $\mathrm{P} 2 \mathrm{HEB} / \mathrm{PLA}$ copolymers difficult as depolymerisation was halted once a lactic acid unit was encountered. However, P(3HB- $b-2 \mathrm{HEB})$ copolymers readily depolymerised the P2HEB block (>90\%) leaving only P3HB chains (Fig. 2). This exemplified the utility of a depolymerisable monomer within a larger macromolecular structure. The thermal pro-

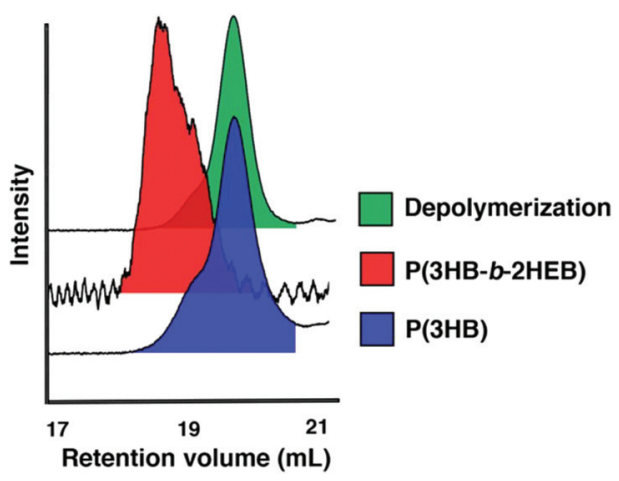

Fig. 2 GPC traces of $\mathrm{P}(3 \mathrm{HB})$ and $\mathrm{P}(2 \mathrm{HEB})$ copolymers and depolymerisation. perties of the polymers were also studied (Table S7†). Pure P2HEB stability was tuned by the copolymer composition where the onset of decomposition $\left(T_{\mathrm{d}, \text { onset }}\right)$ was increased from $219{ }^{\circ} \mathrm{C}$ to $279{ }^{\circ} \mathrm{C}$ in changing from homo to ABA copolymer, with $95 \%$ sample decomposition at $262^{\circ} \mathrm{C}$ and $319^{\circ} \mathrm{C}$ respectively (Fig. S4 $\dagger$ ). Other thermal properties were unexceptional (Table S7 $\dagger$ ) and the tuning of these in homo and copolymers is a current target of our research group.

\section{Conclusions}

In conclusion, the polymerisation of a novel aromatic/aliphatic monomer, 2,3-DHB, was achieved using an aluminium based catalyst or an organocatalyst allowed for the synthesis of very well controlled aromatic/aliphatic polyester from a well defined monomer. Copolymers with lactide and $\beta$-butyrolactone were synthesised with similarly high levels of control. Importantly, when the MeAl[salen] catalyst is used the polymers are easily ring-closed back to monomer at lower concentrations, providing a clean and selective route to recycle the polymer back to monomer. The concentration of the reaction could be manipulated in situ to achieve a fully reversible polymerisation and repolymerisation without a loss of control. We continue to work beyond the scope of this report, exploring benzodioxepinone monomers as components to tune thermal properties in copolymers, build better polymer degradation strategies and expand the monomer scope to substituted DHBs.

\section{Experimental}

\section{General considerations}

All experiments involving moisture- and air-sensitive compounds were performed under a nitrogen atmosphere using an MBraun LABmaster sp glovebox system or a Vigor glovebox equipped with a $-35{ }^{\circ} \mathrm{C}$ freezer and $\left[\mathrm{H}_{2} \mathrm{O}\right]$ and $\left[\mathrm{O}_{2}\right]$ analysers or using standard Schlenk techniques. Gel permeation chromatography (GPC) was used to determine polymer dispersities and was carried out in THF at a flow rate of $1 \mathrm{~mL} \mathrm{~min}^{-1}$ on a Malvern Instruments Viscotek 270 GPC Max triple detection system with $2 \times$ mixed bed styrene/DVB columns $(300 \times$ $7.5 \mathrm{~mm}$ ). GPC analysis was performed using OmniSEC 5.0 software. Polymer molecular weights were calculated by ${ }^{1} \mathrm{H}$ NMR spectroscopy by relative integration of benzylic end-group resonances to polymer resonances. ${ }^{1} \mathrm{H}$ and ${ }^{13} \mathrm{C}$ NMR spectra were recorded at $298 \mathrm{~K}$ with Bruker Avance spectrometers (400 or $500 \mathrm{MHz}$ ) in $\mathrm{CDCl}_{3}$ or $\mathrm{C}_{6} \mathrm{D}_{6}$. TGA samples were heated at $10{ }^{\circ} \mathrm{C} \mathrm{min}^{-1}$ to $150{ }^{\circ} \mathrm{C}$ and held for 10 minutes to remove residual solvent and cooled to room temperature at $10{ }^{\circ} \mathrm{C}$ $\min ^{-1}$ until decomposition was observed.

\section{Materials}

MeAl[salen] was synthesised via modified literature procedures. ${ }^{69,74}$ Benzyl alcohol was dried by refluxing over calcium hydride for 24 hours, distilled under inert atmosphere 
and degassed by three freeze-pump-thaw cycles prior to use. 1,3-Propanediol was distilled under vacuum and stored under inert atmosphere prior to use. Toluene was obtained from an Innovative Technologies solvent purification system, consisting of columns of alumina and copper catalyst and was degassed by three freeze-pump-thaw cycles prior to use. $\mathrm{C}_{6} \mathrm{D}_{6}$ was refluxed over potassium for 72 hours, distilled under inert atmosphere and degassed by three freeze-pump-thaw cycles prior to use. L-Lactide was purified by three vacuum sublimations and dried under reduced pressure for 18 hours prior to use. 2,3-Dihydro-5H-1,4-benzodioxepin-5-one (2,3-DHB) was purchased from AEchem Scientific Corporation and recrystallised three times from EtOAC: hexanes $(50: 50)$ followed by drying under vacuum at $60^{\circ} \mathrm{C}$ for 18 hours prior to use.

\section{Representative homopolymerization of 2,3-DHB}

In a glovebox, 2,3-DHB (116 mg, $0.71 \mathrm{mmol})$, MeAl[salen] (3.8 $\mathrm{mg}, 0.01 \mathrm{mmol}), \mathrm{BnOH}(0.7 \mu \mathrm{L}, 0.01 \mathrm{mmol}$ ) and toluene (150 mg) were added to an ampoule. The ampoule was sealed, removed from the glovebox and placed in a preheated oil bath at $60{ }^{\circ} \mathrm{C}$ for six hours. After six hours, $0.5 \mathrm{~mL}$ of a $10 \% \mathrm{MeOH}$ in $\mathrm{CHCl}_{2}$ solution was added to the ampoule to quench polymerisation. The solution was then added dropwise to cold $\mathrm{MeOH}$ to leave a white solid. Precipitation was repeated twice to remove residual 2,3-DHB.

${ }^{1} \mathrm{H}$ NMR $\left(500 \mathrm{MHz}, \mathrm{CDCl}_{3}\right): \delta 7.72(\mathrm{~m}, 1 \mathrm{H}, \mathrm{Ar} H), 7.36(\mathrm{~m}$, 1H ArH), 6.94-6.88 (m, 2H, ArH), 4.55 (t, $J=5.0 \mathrm{~Hz}, 2 \mathrm{H}, \mathrm{C}(\mathrm{O})-$ $\left.\mathrm{OCH}_{2} \mathrm{CH}_{2} \mathrm{O}\right), 4.25$ (t, $\left.J=5.0 \mathrm{~Hz}, 2 \mathrm{H}, \mathrm{C}(\mathrm{O}) \mathrm{OCH}_{2} \mathrm{CH}_{2} \mathrm{O}\right) .{ }^{13} \mathrm{C} \mathrm{NMR}$ $\left(126 \mathrm{MHz}, \mathrm{CDCl}_{3}\right) \delta 166.00(C(\mathrm{O}) \mathrm{OR}), 158.31,133.70,131.90$, 121.00, 120.85, $114.40(\mathrm{Ar}), 67.40\left(\mathrm{C}(\mathrm{O}) \mathrm{OCH}_{2} \mathrm{CH}_{2} \mathrm{O}\right), 63.05$ (C(O)OCH $\left.\mathrm{OH}_{2} \mathrm{CH}_{2} \mathrm{O}\right)$.

Representative $\mathrm{AB}$ block copolymerization of 2,3-DHB/L-lactide In a glovebox, 2,3-DHB (164 mg, $1.00 \mathrm{mmol}), \mathrm{MeAl}$ [salen] (5.4 mg, $0.01 \mathrm{mmol}), 1,3$-propanediol $(1.0 \mu \mathrm{L}, 0.01 \mathrm{mmol})$ and toluene $(265 \mathrm{mg})$ were added to an ampoule. The ampoule was sealed, removed from the glovebox and placed in a preheated oil bath at $60{ }^{\circ} \mathrm{C}$ for six hours. After six hours, $0.5 \mathrm{~mL}$ of a $10 \%$ $\mathrm{MeOH}$ in $\mathrm{CHCl}_{2}$ solution was added to the ampoule to quench polymerisation. The solution was then added dropwise to cold $\mathrm{MeOH}$ to leave a white solid. Precipitation was repeated twice to remove residual 2,3-DHB. The isolated polymer was then dried under vacuum for 18 hours. To P2HEB (0.005 mmol) was added L-lactide (36 mg, $0.25 \mathrm{mmol}$ ) in toluene $(0.3 \mathrm{~mL})$ at $70{ }^{\circ} \mathrm{C}$. The reaction was stirred for three hours followed by addition on $0.5 \mathrm{~mL}$ of a $10 \% \mathrm{MeOH}$ in $\mathrm{CHCl}_{2}$ solution was added to the ampoule to quench polymerisation. The solution was then added dropwise to cold $\mathrm{MeOH}$ to leave the desired copolymer.

\section{Representative ABA block copolymerization of 2,3-DHB/L- lactide}

In a glovebox, 2,3-DHB (323 mg, $2.00 \mathrm{mmol}), \mathrm{MeAl}[\mathrm{salen}]$ (10.8 mg, $0.02 \mathrm{mmol}$ ), 1,3-propanediol (0.7 mg, $0.01 \mathrm{mmol}$ ) and toluene $(265 \mathrm{mg}$ ) were added to an ampoule. The ampoule was sealed, removed from the glovebox and placed in a pre- heated oil bath at $60^{\circ} \mathrm{C}$ for six hours. After six hours, $0.5 \mathrm{~mL}$ of a $10 \% \mathrm{MeOH}$ in $\mathrm{CHCl}_{2}$ solution was added to the ampoule to quench polymerisation. The solution was then added dropwise to cold $\mathrm{MeOH}$ to leave a white solid. Precipitation was repeated twice to remove residual 2,3-DHB. The isolated polymer was then dried under vacuum for $18 \mathrm{~h}$. To P2HEB (0.01 mmol) was added L-lactide $(72 \mathrm{mg}, 0.5 \mathrm{mmol})$ in toluene $(0.3 \mathrm{~mL})$ at $70{ }^{\circ} \mathrm{C}$. The reaction was stirred for three hours followed by addition on $0.5 \mathrm{~mL}$ of a $10 \% \mathrm{MeOH}$ in $\mathrm{CHCl}_{2}$ solution was added to the ampoule to quench polymerization. The solution was then added dropwise to cold $\mathrm{MeOH}$ to give the desired copolymer.

\section{Representative AB block copolymerization of 2,3-DHB/rac- $\beta$-butyrolactone}

In a glovebox, rac- $\beta$-butyrolactone (100 mg, $1.31 \mathrm{mmol}$ ), MeAl[salen] (14.4 mg, $0.01 \mathrm{mmol}), \mathrm{BnOH}(2.7 \mu \mathrm{L}, 0.01 \mathrm{mmol})$ and toluene $(250 \mathrm{mg})$ were added to an ampoule. The ampoule was sealed, removed from the glovebox and placed in a preheated oil bath at $85{ }^{\circ} \mathrm{C}$ for two hours. After two hours, the ampoule was degassed three times and returned to a glovebox, where 2,3-DHB (215 mg, $1.31 \mathrm{mmol}$ ) was added. The ampoule was then sealed, removed from the glovebox and placed in preheated oil bath at $60{ }^{\circ} \mathrm{C}$ for two hours, followed by addition of $0.5 \mathrm{~mL}$ of a $10 \% \mathrm{MeOH}$ in $\mathrm{CH}_{2} \mathrm{Cl}_{2}$ to the ampoule to quench polymerisation. The solution was then added dropwise to cold $\mathrm{MeOH}$ and filtered to give the desired copolymer.

\section{Acknowledgements}

The authors would like to thank the University of Edinburgh for a Chancellor's Fellowship and the Marie-Curie Actions Programme (Grant FP7-PEOPLE-2013-CIG-618372).

\section{References}

1 C. K. Williams and M. A. Hillmyer, Polym. Rev., 2008, 48, 110.

2 N. Spassky, M. Wisniewski, C. Pluta and A. Le Borgne, Macromol. Chem. Phys., 1996, 197, 2627-2637.

3 T. M. Ovitt and G. W. Coates, J. Am. Chem. Soc., 1999, 121, 4072-4073.

4 T. M. Ovitt and G. W. Coates, J. Polym. Sci., Part A: Polym. Chem., 2000, 38, 4686-4692.

5 T. M. Ovitt and G. W. Coates, J. Am. Chem. Soc., 2002, 124, 1316-1326.

6 M. J. Stanford and A. P. Dove, Macromolecules, 2008, 42, 141-147.

7 M. J. Stanford, R. L. Pflughaupt and A. P. Dove, Macromolecules, 2010, 43, 6538-6541.

8 D. J. A. Cameron and M. P. Shaver, J. Polym. Sci., Part A: Polym. Chem., 2012, 50, 1477-1484.

9 M. P. Shaver and D. J. A. Cameron, Biomacromolecules, 2010, 11, 3673-3679. 
10 G. K. Tennekone, B. D. Wagner and M. P. Shaver, Green Mater., 2013, 2, 31-42.

11 W. Zhao, Y. Wang, X. Liu, X. Chen, D. Cui and E. Y. X. Chen, Chem. Commun., 2012, 48, 6375-6377.

12 J. P. MacDonald, M. P. Parker, B. W. Greenland, D. Hermida-Merino, I. W. Hamley and M. P. Shaver, Polym. Chem., 2015, 6, 1445-1453.

13 C.-M. Dong and G. Liu, Polym. Chem., 2013, 4, 46-52.

14 S. Doppalapudi, A. Jain, W. Khan and A. J. Domb, Polym. Adv. Technol., 2014, 25, 427-435.

15 H. Abe, Y. Doi, Y. Hori and T. Hagiwara, Polymer, 1998, 39, 59-67.

16 Y. Hori, Y. Takahashi, A. Yamaguchi and T. Nishishita, Macromolecules, 1993, 26, 4388-4390.

17 M. Basko, A. Duda, S. Kazmierski and P. Kubisa, J. Polym. Sci., Part A: Polym. Chem., 2013, 51, 4873-4884.

18 J.-H. Kim and J. H. Lee, Polym. J., 2002, 34, 203-208.

19 D. C. Aluthge, C. Xu, N. Othman, N. Noroozi, S. G. Hatzikiriakos and P. Mehrkhodavandi, Macromolecules, 2013, 46, 3965-3974.

20 E. M. Frick and M. A. Hillmyer, Macromol. Rapid Commun., 2000, 21, 1317-1322.

21 E. M. Frick, A. S. Zalusky and M. A. Hillmyer, Biomacromolecules, 2003, 4, 216-223.

22 N. Kasyapi and A. K. Bhowmick, RSC Adv., 2014, 4, 2743927451.

23 B. Lebedev and A. Yevstropov, Makromol. Chem., 1984, 185, 1235-1253.

24 M. Letizia Focarete, M. Scandola, A. Kumar and R. A. Gross, J. Polym. Sci., Part B: Polym. Phys., 2001, 39, 1721-1729.

25 S. Strandman, J. E. Gautrot and X. X. Zhu, Polym. Chem., 2011, 2, 791-799.

26 A. Duda, A. Kowalski, S. Penczek, H. Uyama and S. Kobayashi, Macromolecules, 2002, 35, 4266-4270.

27 Y. Wang and M. Kunioka, Macromol. Symp., 2005, 224, 193206.

28 L. van der Mee, F. Helmich, R. de Brujin, J. A. J. M. Vekemansm, A. R. A. Palmans and E. W. Meijer, Macromolecules, 2006, 39, 5021-5027.

29 S. Namekawa, S. Suda, H. Uyama and S. Kobayashi, Int. J. Biol. Macromol., 1999, 25, 145-151.

30 I. van der Meulen, E. Gubbels, S. Huijser, R. Sablong, C. E. Koning, A. Heise and R. Duchateau, Macromolecules, 2011, 44, 4301-4305.

31 M. P. F. Pepels, M. Bouyahyi, A. Heise and R. Duchateau, Macromolecules, 2013, 46, 4324-4334.

32 H. Fukuzaki, M. Yoshida, M. Asano, M. Kumakura, K. Imasaka, T. Nagai, T. Mashimo, H. Yuasa, K. Imai and H. Yamanaka, Eur. Polym. J., 1990, 26, 1273-1277.

33 I. Tabushi, H. Yamada, H. Matsuzaki and J. Furukawa, J. Polym. Sci., Polym. Lett. Ed., 1975, 13, 447-450.

34 T. L. Simmons and G. L. Baker, Biomacromolecules, 2001, 2, 658-663.

35 T. Liu, T. L. Simmons, D. A. Bohnsack, M. E. Mackay, M. R. Smith and G. L. Baker, Macromolecules, 2007, 40, 6040-6047.
36 I. J. Smith and B. J. Tighe, Makromol. Chem., 1981, 182, 313-324.

37 A. Buchard, D. R. Carbery, M. G. Davidson, P. K. Ivanova, B. J. Jeffery, G. I. Kociok-Köhn and J. P. Lowe, Angew. Chem., Int. Ed., 2014, 53, 13858-13861.

38 E. Hosseini Nejad, A. Paoniasari, C. E. Koning and R. Duchateau, Polym. Chem., 2012, 3, 1308-1313.

39 P. K. Saini, C. Romain, Y. Zhu and C. K. Williams, Polym. Chem., 2014, 5, 6068-6075.

40 N. J. Van Zee and G. W. Coates, Chem. Commun., 2014, 50, 6322-6325.

41 D. J. Brunelle, J. E. Bradt, J. Serth-Guzzo, T. Takekoshi, T. L. Evans, E. J. Pearce and P. R. Wilson, Macromolecules, 1998, 31, 4782-4790.

42 H. Chen, C. Huang, W. Yu and C. Zhou, Polymer, 2013, 54, 1603-1611.

43 H. Chen, W. Yu and C. Zhou, Polym. Eng. Sci., 2012, 52, 91101.

44 P. Fabbri, E. Bassoli, S. B. Bon and L. Valentini, Polymer, 2012, 53, 897-902.

45 G. Giammanco, A. Martinez de Ilarduya, A. Alla and S. Munoz-Guerra, Biomacromolecules, 2010, 11, 2512-2520.

46 N. Gonzalez-Vidal, A. Martinez de Ilarduya and S. MunozGuerra, Eur. Polym. J., 2010, 46, 792-803.

47 P. Hodge, React. Funct. Polym., 2014, 80, 21-32.

48 S. D. Kamau, P. Hodge, R. T. Williams, P. Stagnaro and L. Conzatti, J. Comb. Chem., 2008, 10, 644-654.

49 C. Labruyere, O. Talon, N. Berezina, E. Khousakoun and C. Jerome, $R S C$ Adv., 2014, 4, 38643-38648.

50 Z. A. Mohd. Ishak, K. G. Gatos and J. Karger-Kocsis, Polym. Eng. Sci., 2006, 46, 743-750.

51 E. J. Shin, A. E. Jones and R. M. Waymouth, Macromolecules, 2012, 45, 595-598.

52 A. R. Tripathy, W. J. MacKnight and S. N. Kukureka, Macromolecules, 2004, 37, 6793-6800.

53 Q. Xu, J. Chen, W. Huang, T. Qu, X. Li, Y. Li, X. Yang and Y. Tu, Macromolecules, 2013, 46, 7274-7281.

54 J. H. Youk, A. Boulares, R. P. Kambour and W. J. MacKnight, Macromolecules, 2000, 33, 3600-3605.

55 J. Zhang, Z. Wang, B. Wang, Q. Gou, J. Zhang, J. Zhou, Y. Li, P. Chen and Q. Gu, Polym. Chem., 2013, 4, 16481656.

56 C. A. Rose and K. Zeitler, Org. Lett., 2010, 12, 4552-4555.

57 L. Liu, S. Xu and H. Zhou, Tetrahedron, 2013, 69, 83868391.

58 M. T. Berry, D. Castrejon and J. E. Hein, Org. Lett., 2014, 16, 3676-3679.

59 Z. Shen, H. A. Khan and V. M. Dong, J. Am. Chem. Soc., 2008, 130, 2916-2917.

60 Z. Shen, P. K. Dornan, H. A. Khan, T. K. Woo and V. M. Dong, J. Am. Chem. Soc., 2009, 131, 1077-1091.

61 K. Odelius and A.-C. Albertsson, J. Polym. Sci., Part A: Polym. Chem., 2008, 46, 1249-1264.

62 M. Hakkarainen, G. Adamus, A. Höglund, M. Kowalczuk and A.-C. Albertsson, Macromolecules, 2008, 41, 35473554 . 
63 T. Mathisen, K. Masus and A.-C. Albertsson, Macromolecules, 1989, 22, 3842-3846.

64 A.-C. Albertsson and R. Palmgren, J. Macromol. Sci., Pure Appl. Chem., 1993, 30, 919-931.

65 K. Stridsberg and A.-C. Albertsson, J. Polym. Sci., Part A: Polym. Chem., 1999, 37, 3407-3417.

66 A. Löfgren and A.-C. Albertsson, Polymer, 1995, 36, 37533759.

67 A. Loefgren, A.-C. Albertsson, P. Dubois, R. Jerome and P. Teyssie, Macromolecules, 1994, 27, 5556-5562.

68 J. P. MacDonald and M. P. Shaver, in Green Polymer Chemistry: Biobased Materials and Biocatalysis, American Chemical Society, 2015, ch. 10, vol. 1192, pp. 147-167.
69 P. Hormnirun, E. L. Marshall, V. C. Gibson, R. I. Pugh and A. J. P. White, Proc. Natl. Acad. Sci. U. S. A., 2006, 103, 15343-15348.

70 T. R. Blake and R. M. Waymouth, J. Am. Chem. Soc., 2014, 136, 9252-9255.

71 M. Nelißen, H. Keul and H. Höcker, Macromol. Chem. Phys., 1995, 196, 1645-1661.

72 F. Nederberg, E. F. Connor, T. Glausser and J. L. Hedrick, Chem. Commun., 2001, 2066-2067.

73 D. K. Yoo, D. Kim and D. S. Lee, Macromol. Res., 2006, 14, 510-516.

74 D. A. Atwood, M. S. Hill, J. A. Jegier and D. Rutherford, Organometallics, 1997, 16, 2659-2664. 